\title{
Power Flow Simulation of Flywheel Energy Storage Systems for Tramways
}

\author{
N. Erd, X. Li, A. Binder \\ Institute of Electrical Energy Conversion, Graduate School of Excellence Energy Science and Engineering \\ Technische Universität Darmstadt \\ Darmstadt, Germany \\ nerd@ew.tu-darmstadt.de xli@ew.tu-darmstadt.de abinder@ew.tu-darmstadt.de
}

\begin{abstract}
Energy storage devices, such as flywheel storages, can be used in railway systems, especially tramways, to save energy from being turned into heat in the braking resistor. This paper provides a quantitative analysis for the possible energy savings by using a flywheel energy storage system in a tramway. For this purpose a flywheel is modeled considering various internal losses. Based on the defined operating strategy, the power flow of the traction system is analyzed for a given driving cycle. The energy consumption of a tram with a flywheel system is compared to the consumption of a conventional tram without an energy storage device and a tram with a storage device based on supercaps. Finally, the influence of the grid feedin power limit on the energy savings is analyzed.
\end{abstract}

\section{Key words}

Flywheel, Energy Storage, Tramway, Train, Energy Savings, Supercap

\section{Introduction}

Load profiles of trams show a highly fluctuating power demand due to a driving cycle characterized by many stops [1]. In every acceleration and deceleration period, we observe power peaks due to the traction power needed to accelerate the train and the recuperated power when the train decelerates. This fluctuation causes various energy losses compared to an ideally smooth power demand. Firstly, most tramway grids are not able to feed energy back into the mains, therefore the recovered braking energy has to be consumed within the tramway grid. One possibility is to feed the energy to other trains in vicinity which have a simultaneous power demand. But this preferable scenario is not guaranteed. When the recovered energy cannot be absorbed by the other trains or if they are too far away from the back-feeding train, a braking resistor has to be used to convert the energy into heat.

Instead of turning the electrical energy into heat in the resistor, an onboard energy storage device can be used in order to store the surplus energy and feed the train in the next acceleration period. Thereby a storage device also smooths the power demand and avoids high grid currents, which evoke significant ohmic losses on the catenary. Therefore the potential energy savings are based on both, avoiding the use of the braking resistor and reducing peak currents drawn from the grid. The utilization of the energy saving potential through energy storage devices is economically interesting, since a single tram train has energy costs of ca. $30000 €$ per year [1]. Apart from the energy savings the use of onboard energy storage devices also offers the possibility for centenary-free operation in order to reduce the visual impact of overhead lines [2].

Several technologies are proposed for energy storage devices for railway systems: batteries, supercaps, flywheels and hybrid energy storage systems, which combine batteries with supercaps [3]. Batteries and supercaps are commercially available technologies, whereas flywheels are still in development. In general, batteries have a relatively long recharge time and suffer from significant degradation causing a lifespan of approximately 5000 cycles. Therefore batteries are not suitable for tramway applications, where large numbers of charge/discharge cycles are required (approx. 500 stops/day). Energy storage systems for trams with supercaps are commercially available, but even the slowly degrading supercaps have to be replaced at least one time during the lifetime of the tramway. Flywheels have the advantages of a high power density, similar to supercaps, but offer a higher number of cycles without degradation over time. These are attractive characteristics for the use in energy storage devices for railway applications. However, flywheels are not as highly developed as supercaps due to many technical and economic issues, e.g. system complexity, low energy density, high costs and safety concerns. In comparison to other storage applications, such as domestic storages for surplus PV energy [4], the average storage time in trams is very short. The typical storage time is defined by the average duration of a stop of the train, which is less than a minute. This short storage time keeps flywheels interesting for trams despite the fact, that they show the highest self-discharge rate of all three technologies.

In this paper a simulation model and simulation results are presented to quantify the benefits of an onboard flywheel energy storage system for railway applications. These simulations take the internal losses of the storage devices into account in order to get a realistic estimation 
of the overall energy savings. We modelled a train without a storage device and two different storages: a flywheel energy storage system and a supercap storage device. Comparative results will be given for both technologies with reference to a tram without an energy storage system. The influence of the grid feed-in power limit on the energy savings will be discussed as well.

\section{Tram and Driving Cycle}

The tramway model is set up for the Bombardier Variobahn (Rhein-Neckar). This tram has six motors with $95 \mathrm{~kW}$ nominal power each. The total length of the tram is $40 \mathrm{~m}$ and the train is capable of max. 240 passengers. A schematic picture of the tram is shown in Fig. 1. The particular tram is chosen for modelling, since Bombardier offers a configuration with an energy storage device based on supercaps and driving cycles with overall train power data are available in [1].

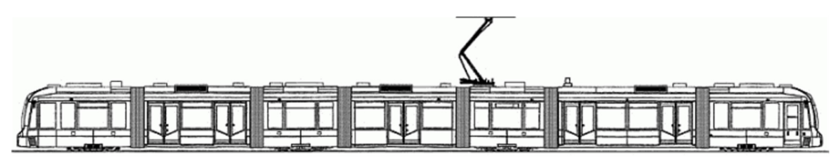

Fig. 1 Seven-car Bombardier Variobahn [5]

The driving cycle, which is used for the simulation is shown in Fig. 2 (top). The driving cycle was measured by Bombardier in the German city Heidelberg and covers one hour. During this urban cycle the tram travels $17.6 \mathrm{~km}$ in total and has an energy consumption of $50.8 \mathrm{kWh}$. Fig. 2 (bottom) shows the overall power demand of the tram in the driving cycle. The train power is negative if the recovered braking power exceeds the power needed for the auxiliary systems, such as air conditioner or lights.
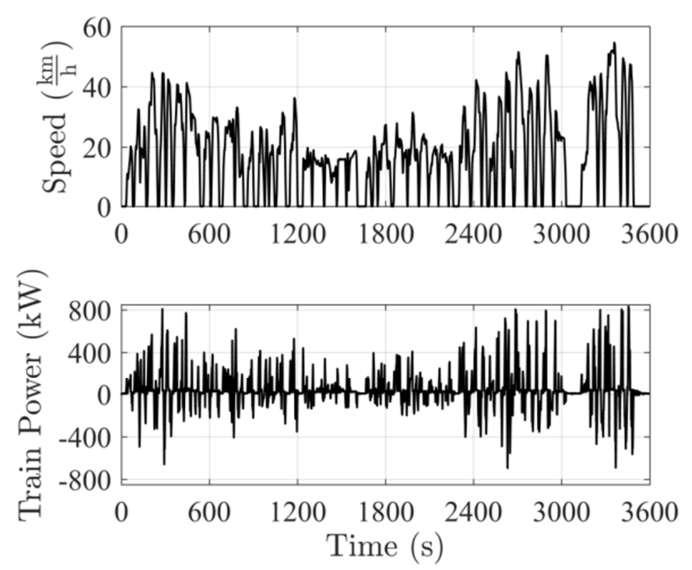

Fig. 2 Urban driving cycle and train power for a Bombardier Variobahn (Rhein-Neckar) according to [1].

Fig. 3 shows the energy density distribution vs. overall train power for the particular driving cycle. This histogram provides detailed information on how much energy is consumed (positive train power) and how much energy is regenerated (negative train power) at which power level (x-axis). On the consumption side we recognize a significant energy consumption around $30 \mathrm{~kW}$ which is caused by auxiliary systems (air conditioning, lights, etc.) in standstill. The remaining energy is consumed in a power range up to $800 \mathrm{~kW}$. On the regenerative side (negative values) we see that most energy is regenerated around a power level of approx. $200 \mathrm{~kW}$ and the amount of energy recovered at a power level over $500 \mathrm{~kW}$ is negligible.

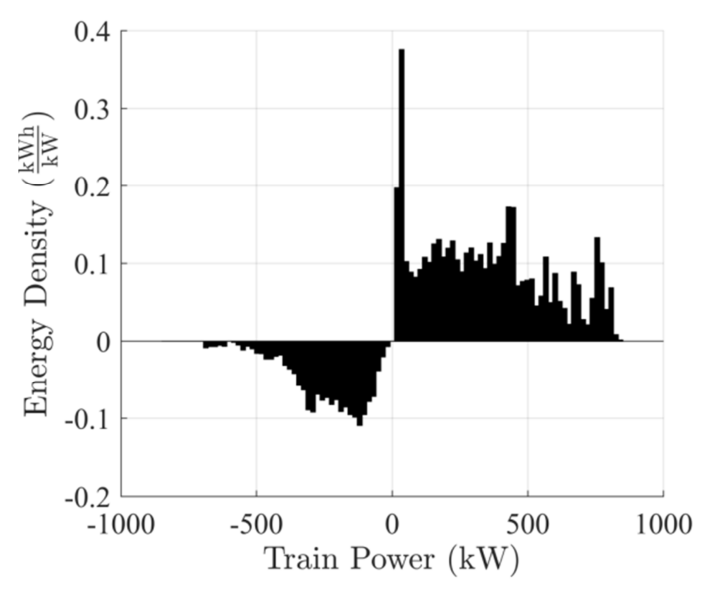

Fig. 3 Energy density distribution vs. power in the driving cycle.

\section{System Description and Modeling}

The flywheel energy storage system considers a flywheel with active magnetic bearings and low pressure atmosphere in order to reduce friction losses. The flywheel rim is coupled through a common shaft to an electrical machine, working as a motor (charging) or generator (discharging).

The flywheel stores kinetic energy $E$, which depends linearly on the inertia $J$ and quadratically on the angular frequency $\omega$ as shown in (1).

$$
E=\frac{1}{2} \cdot J \cdot \omega^{2}
$$

The maximum kinetic energy, which is stored at maximum angular frequency $\omega_{\max }$, is called the capacity $E_{\text {max }}$ as defined in (2).

$$
E_{\max }=\frac{1}{2} \cdot J \cdot \omega_{\max }^{2}
$$

The state of charge $S O C$ is defined in (3).

$$
S O C=\frac{E}{E_{\max }}
$$

The flywheel system is modelled with electrical power constraints in charge and discharge operation following the continuous power limit of electrical machines. The power limit linearly increases with the speed and reaches the maximum value at half of the maximum speed as shown in Fig. 4.

The losses of the flywheel are modeled as three different components:

1. The auxiliary power demand for magnetic bearings, vacuum pump and control system is taken into account as an additional load, which biases the original train power $P_{\text {Train }}$ by a 
constant value $P_{\mathrm{e}}$ if $\omega>0$. The biased train power used in the simulation is $P_{\mathrm{TB}}=P_{\text {Train }}+P_{\mathrm{e}}$.

2. The losses of the electric drive system (machine and inverter) are modelled by a constant charge and discharge efficiency $\eta$.

3. The windage losses inside the containment are modeled by an analytical model following [6] which takes the pressure level, angular speed and geometrical dimensions into account.

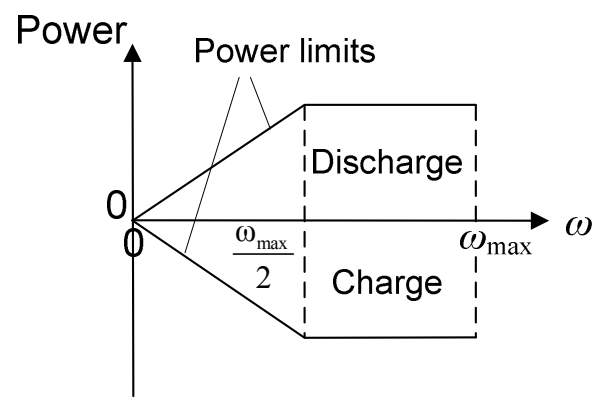

Fig. 4 Power limits of flywheel storage system. The charging and discharging power increase linearly with speed and reach $P_{\max }$ at $0.5 \cdot \omega_{\max }$.

\section{System Operating Strategy}

The simulation software has to allocate the power demand of the train by taking three sources and sinks into account: the grid, the breaking resistor and the flywheel system. The grid can act as a source or sink. In the simulation the grid feed-in power is limited to a constant value to model the dependence of the possible grid feed-in on other loads. The braking resistor only acts as a sink, which turns excessive energy into heat. The flywheel storage system acts as a source if it is discharged or as a sink if it is charged.

In the allocation simulation a simple operating strategy is chosen, which is not depending on additional information. The storage system works in two different operating modes. If the biased train power is positive, the "consumption dominant" mode is active. According to Fig. 5 a) the flywheel feeds the train with the highest priority (1). Only if the biased train power exceeds the power limit of the flywheel or the state of charge is too low, energy from the grid is taken with second priority (2) to cover the remaining energy demand.

If the biased train power becomes negative (Fig. 5 b)), the train acts as a source in generation dominant operation and charges the flywheel with the highest priority (1). If the train power exceeds the charging power or the flywheel is fully charged, the train feeds power to grid with second priority (2). As the grid feed-in power is limited to a constant value, the train power may exceed the power limit of flywheel and grid. In this case the remaining power is converted into heat in the braking resistor with the lowest priority (3).

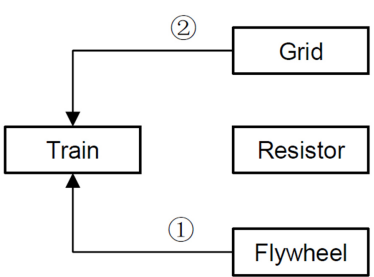

a) consumption dominant

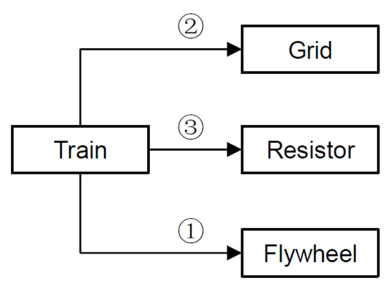

b) generation dominant
Fig. 5 Power flow among components in the two operating modes a) and b). The numbers (1), (2),(3) indicate the priority of the power flow in decreasing order.

\section{Simulation Results: Case Study}

In order to quantify the energy savings due to a flywheel energy storage device, a case study is carried out, which compares the energetic performance of a tram without storage device with a tram with a flywheel energy storage system characterized in Tab. 1 . The grid parameters are equal in both scenarios and summarized in Tab. 2. The feed-in power is limited to a constant value of $50 \mathrm{~kW}$ and the feed-in energy is derated with an efficiency of 0.72 due to ohmic losses in the overhead lines.

Tab. 1 Flywheel parameters in the case study

\begin{tabular}{|c|c|}
\hline Parameter & Value \\
\hline Capacity & $2 \mathrm{kWh}$ \\
\hline $\begin{array}{c}\text { Max. } \\
\text { speed }\end{array}$ & $24000 \mathrm{~min}^{-1}$ \\
\hline $\begin{array}{c}\text { Max. } \\
\text { power }\end{array}$ & $500 \mathrm{~kW}$ \\
\hline Pressure & $0.3 \mathrm{~Pa}$ \\
\hline
\end{tabular}

\begin{tabular}{|c|c|}
\hline Parameter & Value \\
\hline $\begin{array}{c}\text { Charge } \\
\text { efficiency }\end{array}$ & 0.90 \\
\hline $\begin{array}{l}\text { Discharge } \\
\text { efficiency }\end{array}$ & 0.90 \\
\hline $\begin{array}{c}\text { Auxiliary } \\
\text { power }\end{array}$ & $1 \mathrm{~kW}$ \\
\hline $\begin{array}{l}\text { Windage } \\
\text { losses }\end{array}$ & $\begin{array}{r}87 \mathrm{~W} @ 60^{\circ} \mathrm{C} \\
@ \omega_{\max }\end{array}$ \\
\hline
\end{tabular}

Tab. 2 Grid parameters in the case study

\begin{tabular}{|c|c|}
\hline Parameter & Value \\
\hline Max. feed-in power & $50 \mathrm{~kW}$ \\
\hline Feed-in efficiency & 0.72 \\
\hline
\end{tabular}

Fig. 6 shows the speed of the train and the energy allocation plan of the traction system without storage devices for an excerpt of the whole driving cycle. The top graph shows the instantaneous speed of the train. The correlating power is shown with the outline in the bottom graph, with positive values denoting power demand for driving and negative values for braking. The area under the outline demonstrates the energy allocation from different sources and sinks. Without storage devices, the power for driving is completely supplied by the grid (positive blue area) through the overhead line. The regenerative energy during braking is in the first place fed back to grid (negative blue area) with the power limit of $50 \mathrm{~kW}$. Then, the energy exceeding this power limit is wasted in the braking resistor (red area). 


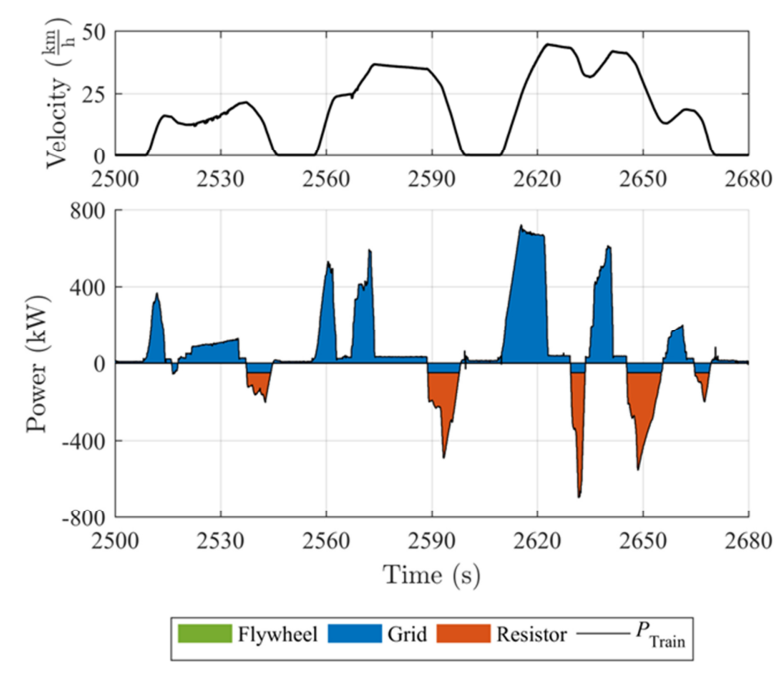

Fig. 6 Energy allocation plan (excerpt) for tram without flywheel energy storage system

In comparison, Fig. 7 shows the operation of the system with a $2 \mathrm{kWh}$ flywheel for the same excerpt of the whole driving cycle. According to the defined priority, the regenerative energy due to deceleration is firstly used to charge the flywheel (negative green area). When the flywheel is full or the power limit of charging is surpassed, the excessive regenerative energy is fed into the grid (negative blue area). The braking resistor (negative red area) takes over only when the power exceeds the possible combined power of the flywheel and the grid. The energy accumulated by the flywheel during deceleration is released to support the train in the next acceleration period (positive green area). The $S O C$ of the flywheel can be seen in the bottom graph of Fig. 7.

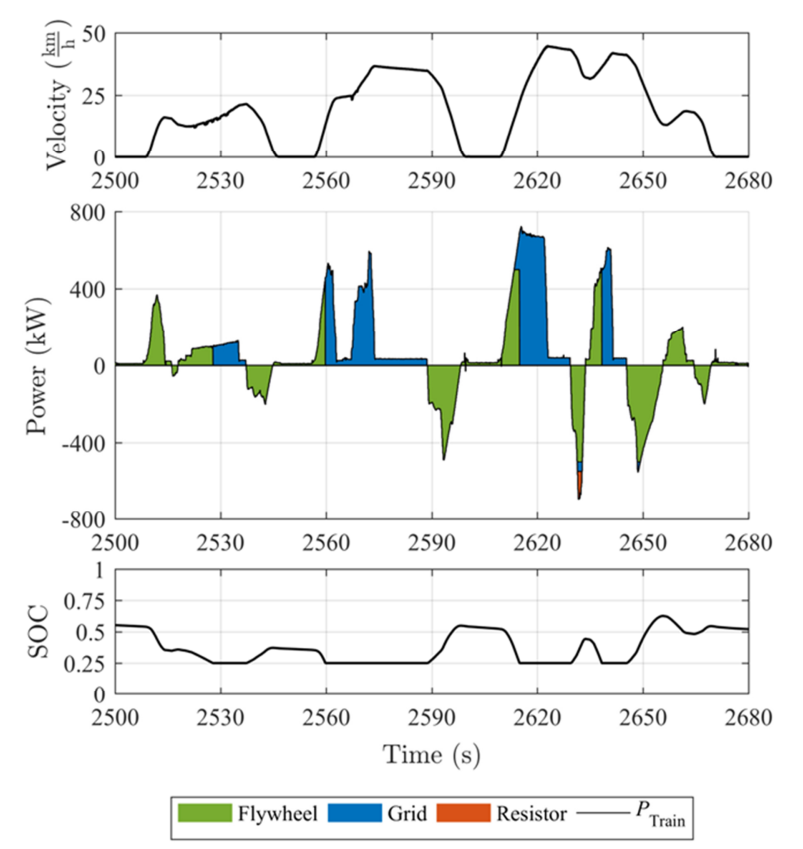

Fig. 7 Energy allocation plan (excerpt) for tram with flywheel energy storage system
Taking the complete driving cycle of one hour into account, the overall energy performance of the two simulated systems is calculated, as shown in Tab. 3 . The use of a flywheel energy storage system reduces the overall energy consumption from $4.21 \mathrm{kWh} / \mathrm{km}$ to $3.3 \mathrm{kWh} / \mathrm{km}$, indicating energy savings of $20.9 \%$. The energy efficiency of the flywheel is about $74.8 \%$, which is close to the round-trip power efficiency of $81 \%$.

Tab. 3 Energy performance of the tram with and without flywheel in the case study

\begin{tabular}{|c|c|c|}
\hline Parameter & With Flywheel & No Flywheel \\
\hline $\begin{array}{c}\text { Overall Energy } \\
\text { Consumption }\end{array}$ & $3.33 \mathrm{kWh} / \mathrm{km}$ & $4.21 \mathrm{kWh} / \mathrm{km}$ \\
\hline Energy Savings & $-20.9 \%$ & $\begin{array}{c}0 \% \\
\text { (Reference) }\end{array}$ \\
\hline $\begin{array}{c}\text { Storage Energy } \\
\text { Efficiency }\end{array}$ & $74.8 \%$ & \\
\hline
\end{tabular}

\section{Comparison with Supercaps}

A second case study is carried out based on the same load profile and the same grid feed-in power limit of $50 \mathrm{~kW}$, but with supercaps as storage device instead of flywheel, in order to make a comparison of the energetic performance for these two technologies. The amount of energy stored in an ideal capacitor is given by

$$
E_{\mathrm{c}}=\frac{1}{2} \cdot C \cdot U^{2}
$$

where $C$ is capacitance and $U$ is voltage. In practice, the internal equivalent series resistance (ESR) causes losses in the capacitor and the leakage current causes the voltage to decay. The parameters of the supercaps modelled are shown in Tab. 4 and chosen according to the datasheet provided in [7]. The inverter efficiency and the auxiliary power demand for cooling and control systems are also considered in the simulation.

Tab. 4 Supercaps parameters in the case study according to [7]

\begin{tabular}{|c|c|}
\hline Parameter & Value \\
\hline Capacity & $2.5 \mathrm{kWh}$ \\
\hline $\begin{array}{c}\text { Max. } \\
\text { voltage }\end{array}$ & $400 \mathrm{~V}$ \\
\hline $\begin{array}{c}\text { Rated } \\
\text { current }\end{array}$ & $2.4 \mathrm{kA}$ \\
\hline ESR & $0.0077 \Omega$ \\
\hline
\end{tabular}

\begin{tabular}{|c|c|}
\hline Parameter & Value \\
\hline $\begin{array}{c}\text { Leakage } \\
\text { current }\end{array}$ & $0.031 \mathrm{~A}$ \\
\hline $\begin{array}{c}\text { Inverter } \\
\text { efficiency }\end{array}$ & 0.95 (Charge) \\
\cline { 2 - 2 } & 0.95 (Discharge) \\
\hline $\begin{array}{c}\text { Auxiliary } \\
\text { power }\end{array}$ & $300 \mathrm{~W}$ \\
\hline
\end{tabular}

Tab. 5 shows the simulation results in comparison with a tram without energy storage device and flywheel. The overall energy consumption is reduced to $3.26 \mathrm{kWh} / \mathrm{km}$ by using supercaps compared to $4.21 \mathrm{kWh}$ for the tram without storage device. This energy consumption is slightly lower than the energy consumption of a tram with a flywheel. The overall energy savings through the supercapacitor storage are $22.6 \%$ at an energy efficiency of $78.6 \%$. Both values are slightly higher compared to the flywheel. The slightly better performance of supercaps comes with the downside of slow degradation of supercaps over time and cycles. 
Tab. 5 Comparison of energy performance of the tram with flywheel and with supercaps in the case study

\begin{tabular}{|c|c|c|c|}
\hline Parameter & $\begin{array}{c}\text { With } \\
\text { Flywheel }\end{array}$ & $\begin{array}{c}\text { With } \\
\text { Supercaps }\end{array}$ & No Storage \\
\hline $\begin{array}{c}\text { Overall Energy } \\
\text { Consumption }\end{array}$ & $\begin{array}{c}3.33 \\
\mathrm{kWh} / \mathrm{km}\end{array}$ & $\begin{array}{c}3.26 \\
\mathrm{kWh} / \mathrm{km}\end{array}$ & $\begin{array}{c}4.21 \\
\mathrm{kWh} / \mathrm{km}\end{array}$ \\
\hline Energy Savings & $-20.9 \%$ & $-22.6 \%$ & $\begin{array}{c}0 \% \\
\text { (Reference) }\end{array}$ \\
\hline $\begin{array}{c}\text { Storage Energy } \\
\text { Efficiency }\end{array}$ & $74.8 \%$ & $78.6 \%$ & \\
\hline
\end{tabular}

\section{Influence of Grid Feed-in Power on Energy Performance}

In the case study we assumed a constant maximum grid feed-in power of $50 \mathrm{~kW}$. This parameter has a strong influence on the energy consumption without an energy storage device, since it determines how much energy will be fed to the braking resistor if no storage device is installed. For a large maximum grid feed-in power we expect a decreasing energy consumption of the tram without a storage system, since the recuperated energy will be fed to the grid instead of being turned into heat.

In order to quantify this dependence a parametric study is conducted. Thereby all parameters of the case study for the tram with the flywheel are preserved (see Tab. 1), but the maximum grid feed-in power is varied and the overall energy consumption is calculated. The results depicted in Fig. 8 show that the overall energy consumption without a flywheel drops from $4.6 \mathrm{kWh} / \mathrm{km}$ at no grid feed-in to $3.4 \mathrm{kWh} / \mathrm{km}$ at $300 \mathrm{~kW}$ maximum grid feed-in power. In the case of a tram with a flywheel energy storage system the overall energy consumption is rather independent of the max. grid feed-in power. The relative energy savings due to the storage are given in Fig. 8 in brackets. The energy savings vary in a broad range from $27 \%$ to $1 \%$ depending on the maximum grid feed-in power.

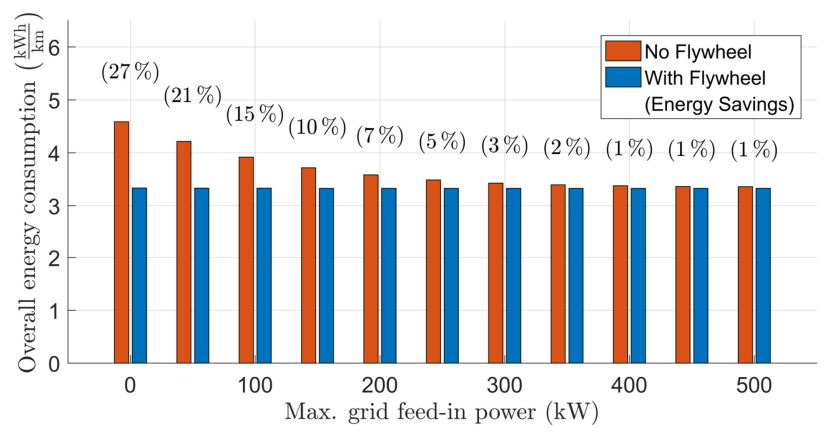

Fig. 8 Overall energy consumption of a tram with (blue) and without (red) flywheel energy storage system depending on the maximum possible grid feed-in power. In brackets the relative energy savings of a tram with a flywheel energy storage system compared to a tram without an energy storage system are given.

The parametric study reveals that the benefit from the storage system in terms of avoiding the use of the breaking resistor is strongly depending on the maximum grid feedin power. A reasonable flywheel design for a particular tram system therefore strongly depends on a reliable determination of the maximum grid feed-in power.

\section{Conclusions}

This paper presents a parametric simulation model for calculating the energy consumption of trams with and without flywheel energy storage systems. The potential energy savings through a flywheel energy storage system strongly depend on the maximum feed-in power. For a low maximum feed-in power a flywheel can save up to $21 \%$ of the total energy consumption, whereas for a grid with a high ability to receive energy the savings decrease to $1 \%$.

A comparative study of using a flywheel and supercaps in the tram shows that the flywheel has slightly lower energy savings than the supercaps. Also the storage energy efficiency of the flywheel $(74.8 \%)$ is lower than the supercaps of $78.6 \%$. However, a complete comparison should also take more factors into account, e.g. the lifetime, overall costs, energy density and safety concerns.

Further simulations are planned with a revised model, which is capable of calculating the current depending ohmic losses on the overhead lines. This will lead to more precise results which take the effect of a smoother grid power into account.

\section{Acknowledgement}

The authors appreciate the financial support by the DFG in the framework of the Excellence Initiative, Darmstadt Graduate School of Excellence Energy Science and Engineering (GSC 1070).

\section{References}

[1] M. Beek and M. Klohr, "RNV und der MITRAC Energy Saver - ein Erfahrungsbericht (RNV and MITRAC Energy-Saver - report of experiences)," ZEVrail, no. 137, pp. 202-209, 2013.

[2] P. Arboleya, P. Bldaguren and U. Armendariz, "Energy is on Board," IEEE Electrification Magazine, pp. 30-41, 2016.

[3] T. Ratniyomachai, S. Hillmansen and P. Tricoli, "Recent developments and applications of energy storage devices in electrified railways," IET Electrical Systems in Transportation, vol. 4, pp. 9-20, 2014.

[4] X. Li, N. Erd und A. Binder, „Evaluation of Flywheel Energy Storage Systems for Residential Photovoltaic Installations, “ in International Symposium on Power Electronics, Electrical Drives, Automation and Motion (SPEEDAM), Capri Island, Italy, 2016.

[5] www.trampicturebook.de, 2016. [Online].

[6] H. Liu, M. Werst, J. J. Hahne and D. Bogard, "Prediction of windage losses of an enclosed high speed composite rotor in low air pressure environments," in Heat Transfer Summer Conf., Las Vegas, USA, 2003.

[7] Maxwell Technologies Inc., „Datasheet K2 Ultracapacitors,"“ 2016. [Online]. 